\title{
A systematic review of patient-reported outcome measures in paediatric otolaryngology
}

\author{
J POWELL ${ }^{1,2}$, S POWELL $^{1}$, A ROBSON $^{3}$ \\ ${ }^{1}$ Department of Paediatric Otolaryngology, Great North Children's Hospital, Newcastle upon Tyne, ${ }^{2}$ Institute of \\ Cellular Medicine, Newcastle University, and ${ }^{3}$ Department of Otolaryngology, North Cumbria University \\ Hospitals, Carlisle, UK
}

\begin{abstract}
Background: Recently, there has been increased emphasis on the development and application of patient-reported outcome measures. This drive to assess the impact of illness or interventions, from the patient's perspective, has resulted in a greater number of available questionnaires. The importance of selecting an appropriate patientreported outcome measure is specifically emphasised in the paediatric population. The literature on patientreported outcome measures used in paediatric otolaryngology was reviewed.

Methods: A comprehensive literature search was conducted using the databases Medline, Embase, Cumulative Index to Nursing and Allied Health Literature, and PsycInfo, using the terms: 'health assessment questionnaire', 'structured questionnaire', 'questionnaire', 'patient reported outcome measures', 'PROM', 'quality of life' or 'survey', and 'children' or 'otolaryngology'. The search was limited to English-language articles published between 1996 and 2016.

Results: The search yielded 656 articles, of which 63 were considered relevant. This included general paediatric patient-reported outcome measures applied to otolaryngology, and paediatric otolaryngology disease-specific patient-reported outcome measures.

Conclusion: A large collection of patient-reported outcome measures are described in the paediatric otolaryngology literature. Greater standardisation of the patient-reported outcome measures used in paediatric otolaryngology would assist in pooling of data and increase the validation of tools used.
\end{abstract}

Key words: Outcome Assessment (Health Care); Health Impact Assessment; Surveys And Questionnaires; Patient Reported Outcome Measures; Quality Of Life; Children

\section{Introduction}

Over recent years, there has been an increased emphasis on the development and application of patient-reported outcome measures. ${ }^{1}$ This drive to assess the impact of illness or interventions, from the patient's perspective, has resulted in a large expansion of available questionnaires. ${ }^{2}$ Patient-reported outcome measures are usually designed to measure one of two broad themes, either patients' perceptions of their general health, or their perceptions of their health in relation to specific diseases or conditions.

The selection of a patient-reported outcome measure requires careful consideration regarding the content of the questionnaire and its relevance to the intended patient group. An appropriate measure is one that is supported by published evidence demonstrating that it is: acceptable to patients, reliable, valid and responsive (sensitive to change). ${ }^{3}$ In addition, evidence for these properties needs to have been obtained in a similar context, and on similar types of patients (in terms of age range, gender, and diagnostic or surgical category) to those whom the patient-reported outcome measure is to be applied.

The importance of selecting an appropriate patientreported outcome measure is specifically emphasised in the paediatric population. Many adult-designed patient-reported outcome measures may contain items that are irrelevant to children (e.g. driving, financial outcomes), or use language and response categories that are not age-appropriate.

We therefore reviewed the current literature on patient-reported outcome measures used in paediatric otolaryngology. This included general paediatric patient-reported outcome measures applied to otolaryngology patients, and otolaryngology disease-specific patient-reported outcome measures. 


\section{Materials and methods}

A comprehensive literature search was conducted on 14 December 2016 using the databases Medline, Embase, Cumulative Index to Nursing and Allied Health Literature, and PsycInfo. The search terms used were: 'health assessment questionnaire', 'structured questionnaire', 'questionnaire', 'patient reported outcome measures', 'PROM', 'quality of life' or 'survey', and 'children' or 'otolaryngology'.

\section{Results}

The search yielded 656 articles. The results were limited to English-language articles published from 1996 to 2016; this yielded 562 articles. Removal of duplicates returned 395 articles. Of these, 82 article abstracts were screened; this yielded a total of 63 relevant articles. Searching the bibliographies of these articles identified further articles that were reviewed.

\section{Disease-specific patient-reported outcome measures}

A large number of questionnaires were identified related to the conditions of otitis media ${ }^{4-14}$ hearing loss, ${ }^{15-18}$ obstructive sleep apnoea, ${ }^{19-30}$ voice disorders, ${ }^{31,32}$ and sore throat and tonsillitis. ${ }^{33-38}$ A number of other questionnaires were infrequently described, related to other specific otolaryngology conditions (Table I). ${ }^{39,40}$ Each tool was of a varying length and underwent variable degrees of validation (Table I). We also identified multiple institutional designed questionnaires, which underwent little or no validation. ${ }^{41-43}$

\section{General patient-reported outcome measures}

The paediatric otolaryngology literature describes a large number of general patient-reported outcome measures that have been utilised. ${ }^{8,20,21,38,44-64}$ Overall, these are extensively validated tools from a non-otolaryngology origin that have been applied to otolaryngology conditions or procedures (Table II).

\section{Discussion}

We identified a large number of both disease-specific and general patient-reported outcome measures that have been used in the paediatric otolaryngology literature. Many publications used a mixture of a diseasespecific patient-reported outcome measures and general patient-reported outcome measures. Disease-specific patient-reported outcome measures are usually more sensitive to differences in one organ system, compared with generic instruments. For otolaryngology, this may be particularly important to detect improvements with treatment. Nevertheless, general tools are important to patients and healthcare commissioners, as they measure more global changes in health status and allow comparison with other conditions. ${ }^{1-3}$

A large number of disease-specific patient-reported outcome measures were identified for the five conditions of otitis media, hearing loss, obstructive sleep apnoea, voice disorders, and sore throat and tonsillitis, which not unsurprisingly are the more common paediatric otolaryngology presentations.

In cases of otitis media, the Otitis Media-6 ('OM-6') questionnaire was by far the most extensively validated

TABLE I

DISEASE-SPECIFIC PATIENT-REPORTED OUTCOME MEASURES USED IN PAEDIATRIC OTOLARYNGOLOGY

\begin{tabular}{|c|c|c|c|c|}
\hline Condition & Patient-reported outcome measure & Number of items & Completed by: & $\begin{array}{l}\text { Ease of } \\
\text { scoring }\end{array}$ \\
\hline \multirow[t]{3}{*}{ Otitis media } & Otitis Media-6 questionnaire ${ }^{4,6-11}$ & 6 & Caregiver & Easy \\
\hline & Otitis Media Outcome-22 questionnaire ${ }^{10,12}$ & 22 & Caregiver & Easy \\
\hline & Chronic Otitis Media-5 survey ${ }^{13,14}$ & 5 & Caregiver & Easy \\
\hline \multirow[t]{3}{*}{ Hearing loss } & $\begin{array}{l}\text { Hearing Environments \& Reflection on Quality of } \\
\text { Life questionnaire }{ }^{15}\end{array}$ & 26 & $\begin{array}{l}\text { Adolescents aged } \\
13-18 \text { years }\end{array}$ & Easy \\
\hline & $\begin{array}{l}\text { Youth Quality of Life Instrument - Deaf \& Hard } \\
\text { of Hearing module }\end{array}$ & 32 & $\begin{array}{l}\text { Adolescents aged } \\
11-18 \text { years }\end{array}$ & Easy \\
\hline & $\begin{array}{l}\text { Paediatric Hearing Impairment Caregiver } \\
\text { Experience questionnaire }\end{array}$ & 68 & Caregiver & Easy \\
\hline \multirow{6}{*}{$\begin{array}{l}\text { Obstructive sleep } \\
\text { apnoea }\end{array}$} & Obstructive Sleep Apnea-18 questionnaire ${ }^{19-25}$ & 18 & Caregiver & Easy \\
\hline & Clinical Assessment Score- $15^{26,27}$ & $\begin{array}{l}15 \text { (10 history, } 5 \\
\text { physical signs) }\end{array}$ & Clinician & Moderate \\
\hline & Rutter Children's Behavior Questionnaire ${ }^{28}$ & 18 & Caregiver & Moderate \\
\hline & Children's Sleep Habits Questionnaire ${ }^{28}$ & 45 & Caregiver & Moderate \\
\hline & Child Health Questionnaire Parent Form $28^{29}$ & 28 & Caregiver & Moderate \\
\hline & OSD-6 instrument ${ }^{30}$ & 6 & Caregiver & Easy \\
\hline \multirow[t]{3}{*}{ Voice disorders } & $\begin{array}{l}\text { Pediatric Voice-Related Quality of Life } \\
\text { survey }^{31,32}\end{array}$ & 10 & Caregiver & Easy \\
\hline & Paediatric Vocal Handicap Index ${ }^{32,65}$ & 23 & Caregiver & Moderate \\
\hline & Pediatric Voice Outcomes Survey ${ }^{31,66,67}$ & 4 & Caregiver & Easy \\
\hline \multirow{2}{*}{$\begin{array}{l}\text { Sore throat \& } \\
\text { tonsillitis }\end{array}$} & Paediatric Throat Disorders Outcome Test ${ }^{33-37}$ & 14 & Caregiver & Easy \\
\hline & Tonsil \& Adenoid Health Status Instrument ${ }^{38}$ & 18 & Caregiver & Easy \\
\hline \multirow[t]{2}{*}{ Other tools } & Pediatric Tracheotomy Health Status Instrument ${ }^{39}$ & 34 & Caregiver & Moderate \\
\hline & Post-Operative Pinnaplasty Questionnaire ${ }^{40}$ & 7 & Caregiver or child & Easy \\
\hline
\end{tabular}

*Identified from the literature review. 
TABLE II

GENERAL PATIENT-REPORTED OUTCOME MEASURES USED IN PAEDIATRIC OTOLARYNGOLOGY*

\begin{tabular}{|c|c|c|c|}
\hline Patient-reported outcome measure & $\begin{array}{l}\text { Number of } \\
\text { items }\end{array}$ & Completed by: & Ease of scoring \\
\hline Glasgow Children's Benefit Inventory ${ }^{44-48}$ & 24 & Caregiver & Easy \\
\hline Pediatric Quality of Life Inventory ${ }^{49-51}$ & 23 & Caregiver or older children & Easy \\
\hline $\begin{array}{l}\text { Pediatric Quality of Life Inventory Family Impact } \\
\text { survey }{ }^{52,53}\end{array}$ & 36 & Caregiver & Easy \\
\hline Child Health Questionnaire ${ }^{38,54-56}$ & 28,50 or 87 & Caregiver or child aged $5-18$ years & $\begin{array}{l}\text { Easy to } \\
\text { moderate }\end{array}$ \\
\hline TNO-AZL Preschool Quality of Life Questionnaire ${ }^{8,58,59}$ & 43 & Caregiver & Easy \\
\hline KINDL-R questionnaire ${ }^{60,61}$ & Various & $\begin{array}{l}\text { Various versions for different age } \\
\text { groups }\end{array}$ & Easy \\
\hline Child Behavior Checklist ${ }^{62}$ & Various & $\begin{array}{l}\text { Various versions for different age } \\
\text { groups }\end{array}$ & Moderate \\
\hline Parenting Stress Index Short Form ${ }^{63}$ & 18 & Caregiver & Easy \\
\hline Caregiver Impact Questionnaire $^{64}$ & 6 & Caregiver & Easy \\
\hline
\end{tabular}

*Identified from the literature review.

tool. ${ }^{4-11}$ The Otitis Media Outcome-22 ('OMO-22') questionnaire was another prominent tool. ${ }^{10,12}$ These tools were principally discriminated by their number of questions, providing a trade-off between response rate and sensitivity to change (lower in longer tools), versus the collection of what may be important information (easier in longer tools). A specific chronic suppurative otitis media tool was also identified, the Chronic Otitis Media-5 ('COM-5') survey. ${ }^{13,14}$

For hearing loss, more frequently generic quality of life (QoL) measures were used. However, diseasespecific tools were also described; these included the adolescent-completed Hearing Environments and Reflection on Quality of Life ('HEAR-QL') questionnaire, ${ }^{15}$ the Youth Quality of Life Instrument - Deaf and Hard of Hearing ('YQOL-DHH') module, ${ }^{16}$ and the caregiver-reported Paediatric Hearing Impairment Caregiver Experience ('PHICE') questionnaire. ${ }^{17,18}$ All of these are fairly lengthy questionnaires related to hearing and general QoL.

A number of obstructive sleep apnoea specific health-related QoL measure were identified. Of these, the Obstructive Sleep Apnea-18 ('OSA-18') questionnaire, which was first described by Franco et al., ${ }^{19}$ was the most widely used and validated QoL survey for the assessment of paediatric obstructive sleep apnoea. $^{20-25}$ A number of other validated tools have also been described. ${ }^{26-30}$ Once again, the greatest discriminator was the length and form of the tool. The Clinical Assessment Score-15 ('CAS-15') stood out as the only clinic-completed tool identified, which included clinical and examination findings.

The literature concerning paediatric voice specific questionnaires was dominated by three frequently used tools, adapted from previously validated adult forms: the Pediatric Voice-Related Quality-of-Life ('PVRQOL') survey, ${ }^{31,32}$ the Paediatric Vocal Handicap Index ('pVHI') $)^{65}$ and the Pediatric Voice Outcomes Survey ('PVOS'). ${ }^{31,66,67}$

Paediatric throat health related QoL was almost entirely reported on using the Paediatric Throat
Disorders Outcome Test ('T-14'). ${ }^{33-37}$ Designed by Hopkins et al., ${ }^{34}$ this 14-item disease-specific questionnaire has been extensively validated and reported upon in children. The only other identified measure was the infrequently used Tonsil and Adenoid Health Status Instrument ('TAHSI'), from which the Paediatric Throat Disorders Outcome Test derives many question items. ${ }^{38}$ A number of other questionnaires were infrequently described, including the Pediatric Tracheotomy Health Status Instrument ('PTHSI') ${ }^{39}$ and the PostOperative Pinnaplasty Questionnaire ('POPQ'). ${ }^{40}$

A number of general patient-reported outcome measures are described in the paediatric otolaryngology literature. The Glasgow Children's Benefit Inventory ('GCBI') was developed by Kubba et al. $^{44}$ to assess health-related QoL pre- and post-intervention, and has been extensively validated and used in a number of otolaryngology interventions. ${ }^{45-48}$ The less widespread use of this tool outside otolaryngology limits the global comparability of its findings with other non-otolaryngology interventions, which may be of importance to certain groups such as commissioners.

Tools such as the Pediatric Quality of Life Inventory ('PedsQL') have also been extensively used in otolaryngology, and in other specialties. It gives a global health overview, and usefully has two forms: the parent proxy report form and the age-specific child self-report form. ${ }^{49-51}$

Similarly, the KINDL-R questionnaire for measuring health-related QoL in children and adolescents, ${ }^{60,61}$ the Child Health Questionnaire (' $\mathrm{CHQ}$ ') ${ }^{38,54-56}$ and the Child Behavior Checklist ('CBCL') 20,21,62 are general patient-reported outcome measures that have different forms for various age groups. These tools have the benefit of age-appropriate questions, but their use would potentially limit comparison of the findings outside of that age group.

Other generic tools have been used in otolaryngology and are completed by the caregiver, such as the TNO-AZL (Netherlands Organisation for Applied Scientific Research Academic Medical Centre) 
Preschool Quality of Life Questionnaire ('TAPQOL'), specifically designed for pre-school children. ${ }^{8,58,59}$ Several generic tools have been described to specifically assess the impact of a disease on the family or caregiver, such as the Pediatric Quality of Life Inventory Family Impact survey, ${ }^{52,53}$ the Parenting Stress Index Short Form ('PSI-SF') ${ }^{63}$ and the Caregiver Impact Questionnaire ('CIQ'). ${ }^{64}$

There were several incidences of patient-reported outcome measures being used inappropriately in the paediatric otolaryngology literature. We found instances where the wording of questionnaires was changed. It is important to note that the wording of a validated patient-reported outcome measure should not be changed because even relatively small alterations can make a considerable difference to the meaning of the questions and consequently to the measurement properties of a questionnaire. ${ }^{2,3}$

We also identified numerous cases where patientreported outcome measures were applied to very different groups or situations to those on which they were validated; for example, the use of adult patient-reported outcome measures, completed by caregivers on the child's behalf, or the use of adult patient-reported outcome measures in adolescents. The term 'paediatric' covers a broad range, and while many of the general patient-reported outcome measures had multiple ageappropriate questions, many of the disease-specific questionnaires were only validated for specific age ranges. Furthermore, patient-reported outcome measures data need to be obtained from relevant patients at the same point in time relative to the date of an intervention or event of interest. ${ }^{2,3}$

It should also be noted that a number of the patientreported outcome measures, particularly the general patient-reported outcome measures, had different versions available, and this needs to be considered when comparing to previously published studies using older versions.

We also identified a distinct lack of consistency regarding the methods for the development of patientreported outcome measures in paediatric otolaryngology. The methods of validation contained many similarities, but were not universal; statistical methods and validation samples sizes varied radically.

The availability of multiple disease-specific and general patient-reported outcome measures is useful to the paediatric otolaryngologist. However, more consistent use of a smaller number of tools would allow for greater standardisation, and would assist in the pooling of data from multiple institutions and studies.

Selecting the appropriate patient-reported outcome measure can be challenging. This is emphasised in the otolaryngology literature from the extensive number of tools used for certain conditions; for example, otitis media. ${ }^{4-14}$

When assessing a patient-reported outcome measure, it is crucial to review the six key areas of: validity, test-retest reliability, precision, responsiveness, acceptance and response rate, and feasibility. ${ }^{1-3}$ Regarding validity, one should consider whether the patient-reported outcome measure assesses what it is supposed to. Changes in patient-reported outcome measure scores can be caused by a multitude of factors, not just the intervention that is being measured. With regard to test-retest reliability, do respondents score similarly on different occasions? Precision is epitomised by the disease-specific or general patient-reported outcome measure debate; can the patient-reported outcome measure discriminate a disease or intervention from a control group? Linking in with precision, responsiveness refers to the ability to measure change after an intervention or change in disease state. Acceptance and response rate are particularly important in paediatric questionnaires. Are the questions appropriate for children (e.g. do they contain questions about employment)? Linking in with acceptance and response rate, a long questionnaire may not be feasible in many clinic settings.

It is also crucial to review the literature on the previous use of any patient-reported outcome measure, considering particularly the age groups that it is appropriate for and whether there are reference data for the comparison group.

It is impossible to have one patient-reported outcome measure that covers all potential research or clinical questions posed in paediatric otolaryngology. For example, the 22-item Otitis Media Outcome-22 questionnaire provides more information than the 6 -item Otitis Media-6 questionnaire, but may have a reduced response rate given its length and reduced sensitivity to change. ${ }^{4}$

Researchers and clinicians should aim to use the most appropriate patient-reported outcome measure for their question, but also consider the comparability with previous studies on that condition. We would advocate, whenever possible, using a disease-specific and/or general patient-reported outcome measure that is frequently cited for the condition of interest, and ensure it is suitably validated, with relevant reference data.

References

1 Nelson EC, Eftimovska E, Lind C, Hager A, Wasson JH, Lindblad S. Patient reported outcome measures in practice. BMJ 2015;350:g7818

2 Dawson J, Doll H, Fitzpatrick R, Jenkinson C, Carr AJ. The routine use of patient reported outcome measures in healthcare settings. BMJ 2010;340:c186

3 Fitzpatrick R, Davey C, Buxton MJ, Jones DR. Evaluating patient-based outcome measures for use in clinical trials. Health Technol Assess 1998;2:1-74

4 Brouwer CN, Maille AR, Rovers MM, Grobbee DE, Sanders EA, Schilder AG. Health-related quality of life in children with otitis media. Int J Pediatr Otorhinolaryngol 2005;69: $1031-41$

5 Timmerman AA, Meesters CM, Speyer R, Anteunis LJ. Psychometric qualities of questionnaires for the assessment of otitis media impact. Clin Otolaryngol 2007;32:429-39

6 Heidemann CH, Godballe C, Kjeldsen AD, Johansen EC, Faber $\mathrm{CE}$, Lauridsen HH. The Otitis Media-6 questionnaire: psychometric properties with emphasis on factor structure and interpretability. Health Qual Life Outcomes 2013;11:201 
7 Grindler DJ, Blank SJ, Schulz KA, Witsell DL, Lieu JE. Impact of otitis media severity on children's quality of life. Otolaryngol Head Neck Surg 2014;151:333-40

8 Kubba H, Swan IR, Gatehouse S. Measuring quality of life in preschool children with sore throats and otitis media using the TAPQOL questionnaire. Otolaryngol Head Neck Surg 2005; 132:647-52

9 Lee J, Witsell DL, Dolor RJ, Stinnett S, Hannley M. Quality of life of patients with otitis media and caregivers: a multicenter study. Laryngoscope 2006;116:1798-804

10 Richards M, Giannoni C. Quality-of-life outcomes after surgical intervention for otitis media. Arch Otolaryngol Head Neck Surg 2002;128:776-82

11 Rosenfeld RM, Goldsmith AJ, Tetlus L, Balzano A. Quality of life for children with otitis media. Arch Otolaryngol Head Neck Surg 1997;123:1049-54

12 Alsarraf R, Jung CJ, Perkins J, Crowley C, Gates GA. Otitis media health status evaluation: a pilot study for the investigation of cost-effective outcomes of recurrent acute otitis media treatment. Ann Otol Rhinol Laryngol 1998;107:120-8

13 Vlastos IM, Kandiloros D, Manolopoulos L, Ferekidis E, Yiotakis I. Quality of life in children with chronic suppurative otitis media with or without cholesteatoma. Int $J$ Pediatr Otorhinolaryngol 2009;73:363-9

14 Habesoglu TE, Habesoglu M, Deveci I, Kulekci S, Kalaycik C, Gokceer T et al. Effect of type I tympanoplasty on the quality of life of children. Ann Otol Rhinol Laryngol 2011;120:326-30

15 Umansky AM, Jeffe DB, Lieu JE. The HEAR-QL: quality of life questionnaire for children with hearing loss. $\mathrm{J} \mathrm{Am} \mathrm{Acad}$ Audiol 2011;22:644-53

16 Patrick DL, Edwards TC, Skalicky AM, Schick B, Topolski TD, Kushalnagar P et al. Validation of a quality-of-life measure for deaf or hard of hearing youth. Otolaryngol Head Neck Surg 2011;145:137-45

17 Meinzen-Derr J, Lim LH, Choo DI, Buyniski S, Wiley S. Pediatric hearing impairment caregiver experience: impact of duration of hearing loss on parental stress. Int $J$ Pediatr Otorhinolaryngol 2008:72:1693-703

18 Lim LH, Xiang L, Wong NL, Yuen KC, Li R. Validation of the Paediatric Hearing Impairment Caregiver Experience (PHICE) Questionnaire. Ann Acad Med Singapore 2014;43: 362-70

19 Franco RA Jr, Rosenfeld RM, Rao M. First place--resident clinical science award 1999. Quality of life for children with obstructive sleep apnea. Otolaryngol Head Neck Surg 2000; 123:9-16

20 Goldstein NA, Fatima M, Campbell TF, Rosenfeld RM. Child behavior and quality of life before and after tonsillectomy and adenoidectomy. Arch Otolaryngol Head Neck Surg 2002;128: $770-5$

21 Tran KD, Nguyen CD, Weedon J, Goldstein NA. Child behavior and quality of life in pediatric obstructive sleep apnea. Arch Otolaryngol Head Neck Surg 2005;131:52-7

22 Mitchell RB. Adenotonsillectomy for obstructive sleep apnea in children: outcome evaluated by pre- and postoperative polysomnography. Laryngoscope 2007;117:1844-54

23 Mitchell RB, Kelly J. Quality of life after adenotonsillectomy for SDB in children. Otolaryngol Head Neck Surg 2005;133: 569-72

24 Kuptanon T, Chukumnerd J, Leejakpai A, Preutthipan A. Reliability and validity of Thai version Quality of Life Questionnaire (OSA-18) for pediatric obstructive sleep apnea. J Med Assoc Thai 2015;98:464-71

25 Kang KT, Weng WC, Yeh TH, Lee PL, Hsu WC. Validation of the Chinese version OSA-18 quality of life questionnaire in Taiwanese children with obstructive sleep apnea. J Formos Med Assoc 2014;113:454-62

26 Goldstein NA, Stefanov DG, Graw-Panzer KD, Fahmy SA, Fishkin S, Jackson A et al. Validation of a clinical assessment score for pediatric sleep-disordered breathing. Laryngoscope 2012;122:2096-104

27 Konka A, Weedon J, Goldstein NA. Cost-benefit analysis of polysomnography versus Clinical Assessment Score-15 (CAS15) for treatment of pediatric sleep-disordered breathing. Otolaryngol Head Neck Surg 2014;151:484-8

28 Zojaji R, Mirzadeh M, Mazloum Farsi Baf M, Khorashadizadeh M, Sabeti HR. The effect of adenotonsillectomy on children's quality of life. Iran J Otorhinolaryngol 2014;26:199-205
29 Georgalas C, Babar-Craig H, Arora A, Narula A. Health outcome measurements in children with sleep disordered breathing. Clin Otolaryngol 2007;32:268-74

30 de Serres LM, Derkay C, Astley S, Deyo RA, Rosenfeld RM, Gates GA. Measuring quality of life in children with obstructive sleep disorders. Arch Otolaryngol Head Neck Surg 2000;126: 1423-9

31 Walz PC, Hubbell MP, Elmaraghy CA. Voice related quality of life in pediatric patients with a history of prematurity. Int $J$ Pediatr Otorhinolaryngol 2014;78:1010-14

32 Boseley ME, Cunningham MJ, Volk MS, Hartnick CJ. Validation of the Pediatric Voice-Related Quality-of-Life survey. Arch Otolaryngol Head Neck Surg 2006;132:717-20

33 Thong G, Davies K, Murphy E, Keogh I. Significant improvements in quality of life following paediatric tonsillectomy: a prospective cohort study. Ir J Med Sci 2017;186:419-25

34 Hopkins C, Fairley J, Yung M, Hore I, Balasubramaniam S, Haggard M. The 14-item Paediatric Throat Disorders Outcome Test: a valid, sensitive, reliable, parent-reported outcome measure for paediatric throat disorders. J Laryngol Otol 2010; 124:306-14

35 Konieczny K, Biggs TC, Caldera S. Application of the Paediatric Throat Disorders Outcome Test (T-14) for tonsillectomy and adenotonsillectomy. Ann R Coll Surg Engl 2013;95: 410-14

36 Konieczny KM, Biggs TC, Pringle MB. A two-year follow-up observational study of the $\mathrm{T}-14$ paediatric throat disorders outcome measure in tonsillectomy and adenotonsillectomy. Ann R Coll Surg Engl 2015;97:382-5

37 Soni-Jaiswal A, Anderco I, Kumar BN. Patient-reported outcomes in children suffering with mild to moderate tonsillitis versus those in children with severe tonsillitis. J Laryngol Otol 2014;128:981-5

38 Goldstein NA, Stewart MG, Witsell DL, Hannley MT, Weaver EM, Yueh B et al. Quality of life after tonsillectomy in children with recurrent tonsillitis. Otolaryngol Head Neck Surg 2008; 138:S9-16

39 Hartnick CJ, Giambra BK, Bissell C, Fitton CM, Cotton RT, Parsons SK. Final validation of the Pediatric Tracheotomy Health Status Instrument (PTHSI). Otolaryngol Head Neck Surg 2002;126:228-33

40 Fraser L, Montgomery J, James H, Wynne DM, MacGregor FB, Clement WA et al. Validation of a family-centred outcome questionnaire for pinnaplasty: a cross-sectional pilot study. Clin Otolaryngol 2016;41:472-80

41 McCormick ME, Ward E, Roberson DW, Shah RK, Stachler RJ, Brenner MJ. Life after tracheostomy: patient and family perspectives on teaching, transitions, and multidisciplinary teams. Otolaryngol Head Neck Surg 2015;153:914-20

42 Connor MP, Dion GR, Borgman M, Maturo S. The pediatric sedation unit: a prospective analysis of parental satisfaction. Int J Pediatr Otorhinolaryngol 2014;78:2165-8

43 Boss EF, Thompson RE. Patient experience in the pediatric otolaryngology clinic: does the teaching setting influence parent satisfaction? Int J Pediatr Otorhinolaryngol 2013;77:59-64

44 Kubba H, Swan IR, Gatehouse S. The Glasgow Children's Benefit Inventory: a new instrument for assessing healthrelated benefit after an intervention. Ann Otol Rhinol Laryngol 2004;113:980-6

45 Langille M, El-Hakim H. Pediatric inferior turbinoplasty with or without adenoidectomy: preliminary report on improvement of quality of life, symptom control, and safety. J Otolaryngol Head Neck Surg 2011;40:420-6

46 Schwentner I, Schmutzhard J, Schwentner C, Abraham I, Hofer S, Sprinzl GM. The impact of adenotonsillectomy on children's quality of life. Clin Otolaryngol 2008;33:56-9

47 de Wolf MJ, Hol MK, Mylanus EA, Snik AF, Cremers CW. Benefit and quality of life after bone-anchored hearing aid fitting in children with unilateral or bilateral hearing impairment. Arch Otolaryngol Head Neck Surg 2011;137:130-8

48 Schwentner I, Schwentner C, Schmutzhard J, Radmayr C, Grabher G, Sprinzl G et al. Validation of the German Glasgow children's benefit inventory. J Eval Clin Pract 2007; 13:942-6

49 Naiboglu B, Kulekci S, Kalaycik C, Sheidaei S, Toros SZ, Egeli E. Improvement in quality of life by adenotonsillectomy in children with adenotonsillar disease. Clin Otolaryngol 2010;35: 383-9 
50 Garetz SL, Mitchell RB, Parker PD, Moore RH, Rosen CL, Giordani B et al. Quality of life and obstructive sleep apnea symptoms after pediatric adenotonsillectomy. Pediatrics 2015; 135:e477-86

51 Lindman JP, Lewis LS, Accortt N, Wiatrak BJ. Use of the Pediatric Quality of Life Inventory to assess the health-related quality of life in children with recurrent respiratory papillomatosis. Ann Otol Rhinol Laryngol 2005;114:499-503

52 Varni JW, Sherman SA, Burwinkle TM, Dickinson PE, Dixon P The PedsQL Family Impact Module: preliminary reliability and validity. Health Qual Life Outcomes 2004;2:55

53 Blank SJ, Grindler DJ, Schulz KA, Witsell DL, Lieu JE. Caregiver quality of life is related to severity of otitis media in children. Otolaryngol Head Neck Surg 2014;151:348-53

54 Georgalas C, Tolley N, Kanagalingam J. Measuring quality of life in children with adenotonsillar disease with the Child Health Questionnaire: a first U.K. study. Laryngoscope 2004; 114:1849-55

55 Baldassari CM, Mitchell RB, Schubert C, Rudnick EF. Pediatric obstructive sleep apnea and quality of life: a meta-analysis. Otolaryngol Head Neck Surg 2008;138:265-73

56 Cunningham MJ, Chiu EJ, Landgraf JM, Gliklich RE. The health impact of chronic recurrent rhinosinusitis in children. Arch Otolaryngol Head Neck Surg 2000;126:1363-8

57 Randhawa PS, Cetto R, Chilvers G, Georgalas C, Narula AA. Long-term quality-of-life outcomes in children undergoing adenotonsillectomy for obstructive sleep apnoea: a longitudinal study. Clin Otolaryngol 2011;36:475-81

58 Raat H, Mohangoo AD, Grootenhuis MA. Pediatric healthrelated quality of life questionnaires in clinical trials. Curr Opin Allergy Clin Immunol 2006;6:180-5

59 Raat H, Botterweck AM, Landgraf JM, Hoogeveen WC, Essink-

Bot ML. Reliability and validity of the short form of the child health questionnaire for parents (CHQ-PF28) in large random school based and general population samples. J Epidemiol Community Health 2005;59:75-82

60 Loy B, Warner-Czyz AD, Tong L, Tobey EA, Roland PS. The children speak: an examination of the quality of life of pediatric cochlear implant users. Otolaryngol Head Neck Surg 2010;142 247-53
61 Morettin M, Santos MJ, Stefanini MR, Antonio F de L, Bevilacqua MC, Cardoso MR. Measures of quality of life in children with cochlear implant: systematic review. Braz $J$ Otorhinolaryngol 2013;79:375-81

62 Mazefsky CA, Anderson R, Conner CM, Minshew N. Child Behavior Checklist scores for school-aged children with autism: preliminary evidence of patterns suggesting the need for referral. J Psychopathol Behav Assess 2011;33:31-7

63 Davies K, Batra K, Mehanna R, Keogh I. Pediatric epistaxis: epidemiology, management \& impact on quality of life. Int $J$ Pediatr Otorhinolaryngol 2014;78:1294-7

64 Boruk M, Lee P, Faynzilbert Y, Rosenfeld RM. Caregiver wellbeing and child quality of life. Otolaryngol Head Neck Surg 2007; 136:159-68

65 Zur KB, Cotton S, Kelchner L, Baker S, Weinrich B, Lee L. Pediatric Voice Handicap Index ( $p$ VHI): a new tool for evaluating pediatric dysphonia. Int J Pediatr Otorhinolaryngol 2007; 71:77-82

66 Hartnick CJ. Validation of a pediatric voice quality-of-life instrument: the pediatric voice outcome survey. Arch Otolaryngol Head Neck Surg 2002;128:919-22

67 Merati AL, Keppel K, Braun NM, Blumin JH, Kerschner JE. Pediatric Voice-Related Quality of Life: findings in healthy children and in common laryngeal disorders. Ann Otol Rhinol Laryngol 2008;117:259-62

Address for correspondence:

Mr Jason Powell

Department of Paediatric Otolaryngology,

Great North Children's Hospital,

Newcastle upon Tyne NE1 4LP, UK

Fax: +44 1912231246

E-mail: jason.powell@doctors.org.uk

Mr J Powell takes responsibility for the integrity of the content of the paper

Competing interests: None declared 